Louisiana State University

LSU Digital Commons

2-1-2005

\title{
Multiplex polymerase chain reaction for simultaneous quantitation of human nuclear, mitochondrial, and male $Y$ - chromosome DNA: Application in human identification
}

\author{
Jerilyn A. Walker \\ Ctr. Bio-Modular Microsystems \\ Dale J. Hedges \\ Ctr. Bio-Modular Microsystems \\ Benjamin P. Perodeau \\ Ctr. Bio-Modular Microsystems \\ Kate E. Landry \\ Ctr. Bio-Modular Microsystems \\ Nadica Stoilova \\ Ctr. Bio-Modular Microsystems
}

See next page for additional authors

Follow this and additional works at: https://digitalcommons.Isu.edu/biosci_pubs

\section{Recommended Citation}

Walker, J., Hedges, D., Perodeau, B., Landry, K., Stoilova, N., Laborde, M., Shewale, J., Sinha, S., \& Batzer, M. (2005). Multiplex polymerase chain reaction for simultaneous quantitation of human nuclear, mitochondrial, and male Y-chromosome DNA: Application in human identification. Analytical Biochemistry, 337 (1), 89-97. https://doi.org/10.1016/j.ab.2004.09.036

This Article is brought to you for free and open access by the Department of Biological Sciences at LSU Digital Commons. It has been accepted for inclusion in Faculty Publications by an authorized administrator of LSU Digital Commons. For more information, please contact ir@lsu.edu. 


\section{Authors}

Jerilyn A. Walker, Dale J. Hedges, Benjamin P. Perodeau, Kate E. Landry, Nadica Stoilova, Meredith E. Laborde, Jaiprakash Shewale, Sudhir K. Sinha, and Mark A. Batzer 


\title{
Multiplex polymerase chain reaction for simultaneous quantitation of human nuclear, mitochondrial, and male Y-chromosome DNA: application in human identification
}

\author{
Jerilyn A. Walker ${ }^{\mathrm{a}}$, Dale J. Hedges ${ }^{\mathrm{a}}$, Benjamin P. Perodeau ${ }^{\mathrm{a}}$, Kate E. Landry, \\ Nadica Stoilova $^{a}$, Meredith E. Laborde ${ }^{a}$, Jaiprakash Shewale ${ }^{b}$, Sudhir K. Sinha ${ }^{b}$, \\ Mark A. Batzer ${ }^{a}$ **

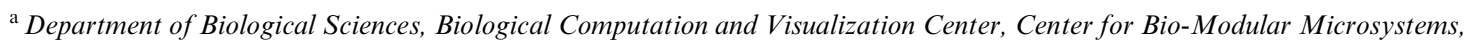 \\ Louisiana State University, 202 Life Sciences Building, Baton Rouge, LA 70803, USA \\ ${ }^{\mathrm{b}}$ ReliaGene Technologies, Inc., 5525 Mounes Street, Suite 101, New Orleans, LA 70123, USA
}

Received 20 August 2004

Available online 9 December 2004

\begin{abstract}
Human forensic casework requires sensitive quantitation of human nuclear (nDNA), mitochondrial (mtDNA), and male Y-chromosome DNA from complex biomaterials. Although many such systems are commercially available, no system is capable of simultaneously quantifying all three targets in a single reaction. Most available methods either are not multiplex compatible or lack human specificity. Here, we report the development of a comprehensive set of human-specific, target-specific multiplex polymerase chain reaction (PCR) assays for DNA quantitation. Using TaqMan-MGB probes, our duplex qPCR for nDNA/mtDNA had a linear quantitation range of $100 \mathrm{ng}$ to $1 \mathrm{pg}$, and our triplex qPCR assay for nDNA/mtDNA/male Y DNA had a linear range of 100-0.1 ng. Human specificity was demonstrated by the accurate detection of 0.05 and $5 \%$ human DNA from a complex source of starting templates. Target specificity was confirmed by the lack of cross-amplification among targets. A high-throughput alternative for human gender determination was also developed by multiplexing the male Y primer/probe set with an X-chromosome-based system. Background cross-amplification with DNA templates derived from 14 other species was negligible aside from the male Y assay which produced spurious amplifications from other nonhuman primate templates. Mainstream application of these assays will undoubtedly benefit forensic genomics.
\end{abstract}

(C) 2004 Elsevier Inc. All rights reserved.

Keywords: Forensic genomics; Triplex

Forensic DNA specimens are commonly matched to alleged criminal suspects in modern law enforcement using human identification systems validated according to the DNA Advisory Board's Quality Assurance Standards. These DNA testing systems typically involve the amplification of highly polymorphic short tandem

\footnotetext{
* Corresponding author. Fax: +1 2255787113.

E-mail address: mbatzer@1su.edu (M.A. Batzer).
}

repeats (STRs) ${ }^{1}$ by polymerase chain reaction (PCR). AmpFlSTR Profiler Plus and COfiler, Powerplex, Powerplex-Y, and Y-PLEX 12 are examples of commonly used multiplex systems for genotyping polymorphic STRs residing in the human nuclear (nDNA) and male Y-chromosome DNA. In general, these systems require

\footnotetext{
${ }^{1}$ Abbreviations used: STRs, short tandem repeats; HV, hypervariable; NTC, no-template control.
} 
about $0.1-2.0 \mathrm{ng}$ of DNA template for analysis [1]. When DNA evidence is limited, analysis of human mitochondrial DNA (mtDNA) targets is often employed because of the high copy number of mitochondria and mtDNA molecules in each cell [2]. In some cases, DNA evidence obtained from criminal investigations or forensic anthropology studies may be degraded and/or contain nonhuman contaminants. Consequently, an essential precursor to standard forensic analyses is the sensitive quantitation of human nuclear, mitochondrial, and male Y-chromosome DNA from complex biomaterials.

Commercially available products for human DNA quantitation include AluQuant (Promega), and Quantifiler human and Quantifiler Y (Applied Biosystems). In addition, several real-time PCR assays have been reported for nDNA quantitation [3-7] and for the simultaneous quantitation of nDNA and mtDNA [8,9]. However, there are limitations to these previously reported methods. Many of these systems are not human specific and amplify both human and nonhuman primate DNA $[3-5,7,9]$. Some methods are not target specific in that the mtDNA assay also amplifies a product from the nuclear genome [9] or is designed in the hypervariable (HV) region of the mitochondrial genome rather than in the conserved region, thereby increasing the probability of target mismatches and inaccurate quantitation [8]. Most of these systems are not multiplex compatible (Quantifiler, Quantifiler Y, AluQuant) [3,6], resulting in the possible depletion of valuable DNA specimens prior to subsequent analyses. Most importantly, no system that meets all of these criteria, human specificity, target specificity, high sensitivity, and multiplex compatibility, is currently available.
To overcome the limitations associated with previously reported methods for human DNA quantitation, we have used a systematic approach to the design and implementation of a comprehensive set of multiplex PCR assays for the rapid detection and quantitation of human DNA using TaqMan-MGB probes. These include a duplex qPCR assay for human nDNA and mtDNA, the first triplex qPCR assay for the simultaneous quantitation of human nDNA, mtDNA, and male $\mathrm{Y}$ chromosome DNA, and a duplex PCR assay for human sex typing.

\section{Materials and methods}

\section{PCR primer and probe design}

Oligonucleotide PCR primers and TaqMan-MGB probes were designed using Primer Express software (Applied Biosystems). Primers were purchased from Sigma-Genosys, and probes were purchased from Applied Biosystems (Table 1). Each primer pair was evaluated in our laboratory using standard agarose gel electrophoresis prior to the purchase of the probes.

The human nuclear DNA quantification assay is an intra-Alu-based design incorporating the 7-bp duplicated region characteristic of the $\mathrm{Yb}$ lineage of Alu subfamilies and an AluY $\mathrm{Yb} 8$ diagnostic base at the $3^{\prime}$ end of the forward primer (Fig. 1).

Complete mitochondrial genome sequences were downloaded from the University of Montreal website (http://megasun.bch.umontreal.ca/ogmp/projects/other/ mt_list.html). Human sequence was selected from 36 different Homo sapiens accession loci and aligned using

Table 1

Oligonucleotide primers and probes for human DNA quantitation assays

\begin{tabular}{|c|c|c|c|c|}
\hline Assay & Forward primer & Reverse primer & Probe & Size (bP) \\
\hline mtDNA & $\begin{array}{l}\text { 5'AATATTAAACACAAAC } \\
\text { TACСACСТАСCТ } 3^{\prime}\end{array}$ & $\begin{array}{l}\text { 5'TGGTTCTCAGGGTTTGTT } \\
\text { ATAA3' }\end{array}$ & $\begin{array}{l}\text { 5' FAM CCTCACCAAAGCCCATA3' } \\
\text { MGBNFQ }\end{array}$ & 79 \\
\hline nDNA & $\begin{array}{l}\text { 5'CTTGCAGTGAGCCGA } \\
\text { GATT3' }\end{array}$ & $\begin{array}{l}\text { 5'GAGACGGAGTCTCGCTC } \\
\text { TGTC3' }\end{array}$ & $\begin{array}{l}\text { 5'VIC ACTGCAGTCCGCAGTCCGGCCT3' } \\
\text { MGBNFQ }\end{array}$ & 71 \\
\hline Y-male & $\begin{array}{l}\text { 5'CACCTACTGTGCCAGA } \\
\text { CAATGTG3' }\end{array}$ & $\begin{array}{l}\text { 5'CCCATGCCATGTTTGTCA } \\
\text { TACT3' }\end{array}$ & $\begin{array}{l}\text { 5'NED TAGGCTCTAGGAATACAAAA3' } \\
\text { MGBNFQ }\end{array}$ & 69 \\
\hline $\mathrm{X}-\mathrm{Chr}$ & $\begin{array}{l}\text { 5'CCACGAACTTTAATTA } \\
\text { GTCACCTACTGT3' }\end{array}$ & $\begin{array}{l}\text { 5'ATTCСТСТСТССАТTATG } \\
\text { TTCAATTACA3' }\end{array}$ & $\begin{array}{l}\text { 5'VIC CAGACAATGTGATAAATG3' } \\
\text { MGBNFQ }\end{array}$ & 77 \\
\hline
\end{tabular}

$$
\begin{aligned}
& \text { Al UY GAACCCGGGAGGCGGACTTGCAGTGAGCCGAGATCGCGCCactgcaCtc } 250
\end{aligned}
$$

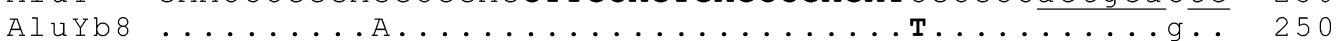

$$
\begin{aligned}
& \text { AluY CA----- gCCtGGGCGCAGAGCGAGACTCCGTCTCAAAAAA } 287
\end{aligned}
$$

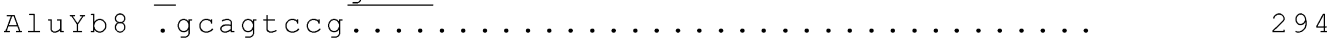

Fig. 1. Sequence alignment of a portion of the $A l u \mathrm{Y}$ and $A l u \mathrm{Yb} 8$ consensus sequences used in the design of our nDNA quantitation assay. The dots represent the same nucleotide as the ancestral $A l u \mathrm{Y}$ consensus sequence. Deletions are shown as dashes and the subfamily diagnostic mutations are shown as the correct base. The intra- $A l u \mathrm{Yb} 8$ oligonucleotide primers are shown in boldface and the TaqMan-MGB probe labeled with $5^{\prime}$ VIC is shown in lowercase underlined font. 
MegAlign with the ClustalW algorithm and the default settings (DNAstar Version 5.0 for Windows) to obtain a human consensus sequence in the conserved region of the mitochondrial genome. Next, sequences from pygmy chimpanzee (Pan paniscus, $n=1$ ), common chimpanzee (Pan troglodytes, $n=2$ ), and Gorilla (Gorilla gorilla, $n=2$ ) were aligned with the human consensus sequence to determine regions that were human specific. Finally, sequence from a region of human chromosome 1 nearly identical to the mitochondrial sequence (H. sapiens chromosome 1 genomic contig gi|29791381|ref|NT_034471. 3|Hs1_34633[29791381]) was downloaded from the National Center for Biotechnology Information (www.ncbi.nlm.nih.gov) and aligned with the previous mitochondrial genome sequences. A consensus alignment of these data is shown in Fig. 2, comparing a previously reported assay [9] to our design. Our humanspecific mitochondrial assay was designed to incorporate human/chimp mismatches at the 3' ends of each primer and a single mtDNA/nuclear DNA mismatch at the 3' end of the reverse primer (Fig. 2). A complete list of the mitochondrial sequences used in the alignments is on our website http://batzerlab.lsu.edu.

The sex chromosome assays were designed around a 90-bp deletion on the human $\mathrm{X}$ chromosome in an $\mathrm{X}-\mathrm{Y}$ homologous region (Fig. 3). Primers are shown in boldface font and the chromosome-specific probes are shown in lower case underlined font. The deletion starts at X position 89810740 as determined by BLAT (The BLAST-like Alignment Tool) http://genome.ucsc.edu/ cgi-bin/hgBlat (7 June 2004). This X deletion was discovered during previous work in our laboratory [10] and is being reported here for the first time. We tested the locus for fixation and human gender identification in 593 diverse humans of known gender (Table 3) with 100\% accuracy. The DNA samples were composed of individuals from different geographic origins to test for possible population-specific mutations that might impact the amplification of the locus. Of the 593 DNA samples tested, 545 were obtained from paternity/identity cases and the remaining samples were purchased from Coriell Cell Repositories (Camden, NJ). Forward primer 5'CCACAAACTTTAATTAGTCACCTACTGT3' and reverse primer 5'ATTCCTCTCTCCATTATGTTCAA TTACA3' were used to PCR amplify a 77-bp fragment on the human $\mathrm{X}$ chromosome and a 167-bp fragment on the human $\mathrm{Y}$ chromosome and products were resolved on a $2 \%$ agarose gel stained with ethidium bromide.

\section{PCR amplification}

Quantitative PCR experiments were performed using an ABI Prism 7000 sequence detection system and Taq-

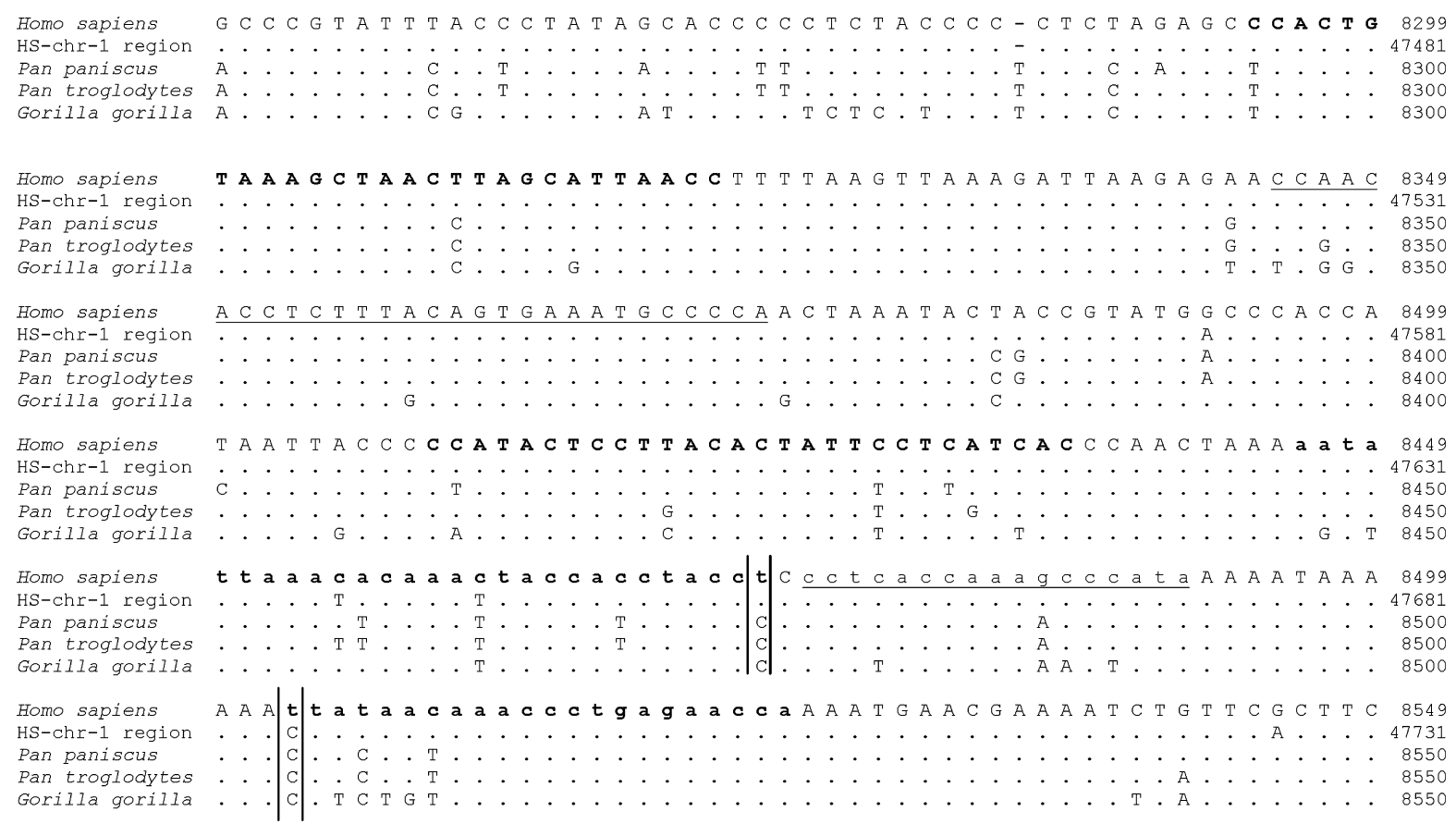

Fig. 2. Sequence alignment of a part of the human mitochondrial consensus sequence. The alignment shows positions $8250-8550$ of human mtDNA, aligned for comparison with nonhuman primate mtDNA consensus sequences and a target from the human nuclear genome with $98 \%$ sequence similarity to the human mtDNA consensus sequence. The dots represent the same nucleotide as the human consensus sequence. Deletions are shown as dashes and mutations are shown as the correct base. A previously reported assay [9] has primers in boldface uppercase (mt-8294F and $\mathrm{mt}-8436 \mathrm{R}$ ) and probe (mt-8345) in underlined uppercase, while our design has primers in boldface lowercase (mt-8446F and $\mathrm{mt}-8525 \mathrm{R})$ and probe (mt-8475) in underlined lowercase. 


\title{
$X$-chromosome \\ Y-chromosome \\ $\mathrm{X}$-chromosome \\ Y-chromosome \\ X-chromosome \\ $Y$-chromosome \\ X-chromosome \\ Y-chromosome \\ X-chromosome \\ Y-chromosome
}

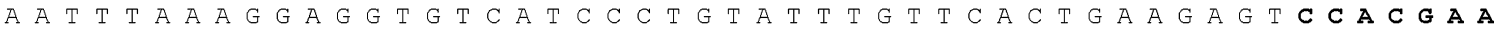

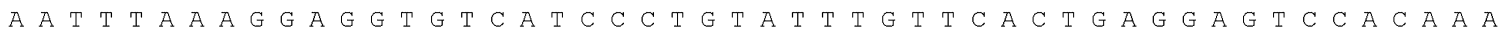

С T T T A A T T A G T C A C C T A C T G T G C C a g a C a a $t$ g $t$ g $\ldots \ldots$

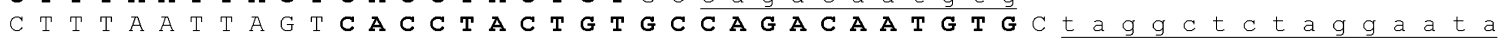

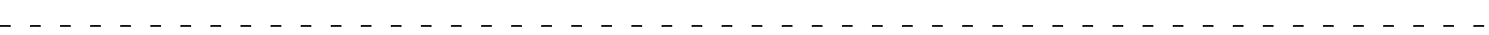

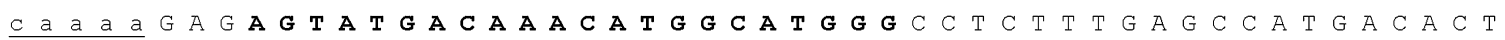

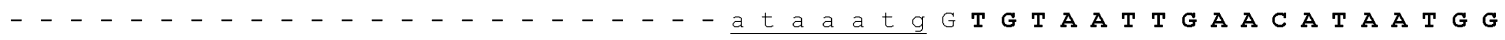

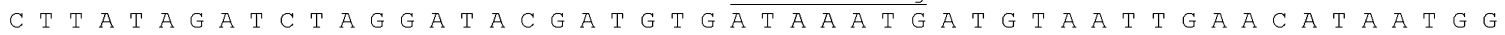

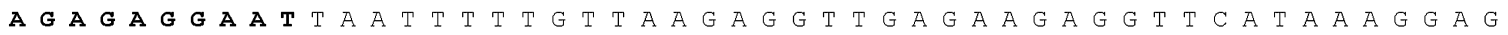
$A G A G A G G A A T T A A T T T T T G T T A A G A G G T T G A G A A G A G G T T C A T A A A G G A G$
\end{abstract}

Fig. 3. Sequence alignment of a portion of the homologous region of the human sex chromosomes. The dashes represent a 90-bp deletion specific to the human X chromosome. Primers are shown in boldface font and the chromosome-specific TaqMan-MBG probes are shown in lowercase underlined font.

Table 2

Compositions of mixed-DNA test samples

\begin{tabular}{|c|c|c|c|c|c|c|c|c|}
\hline \multirow[t]{2}{*}{ Contents mix } & \multicolumn{2}{|c|}{ Human male } & \multicolumn{2}{|l|}{ Dog } & \multicolumn{2}{|l|}{ Cat } & \multicolumn{2}{|c|}{ Total template } \\
\hline & DNA (ng) & $\%$ & DNA (ng) & $\%$ & DNA (ng) & $\%$ & DNA (ng) & $\%$ \\
\hline 1 & 50 & 50 & 25 & 25 & 25 & 25 & 100 & 100 \\
\hline 2 & 5 & 50 & 2.5 & 25 & 2.5 & 25 & 10 & 100 \\
\hline 3 & 0.5 & 5 & 5 & 50 & 4.5 & 45 & 10 & 100 \\
\hline 4 & 0.05 & 0.5 & 5 & 50 & 4.95 & 49.5 & 10 & 100 \\
\hline 5 & 0.005 & 0.05 & 5 & 50 & 4.995 & 49.95 & 10 & 100 \\
\hline
\end{tabular}

Table 3

DNA samples tested for gender identification

\begin{tabular}{lccc}
\hline Population & Males & Females & Total \\
\hline African-American & 150 & 141 & 291 \\
European-American & 49 & 60 & 109 \\
Hispanic-American & 9 & 7 & 16 \\
North American & 75 & 54 & 129 \\
South American & 7 & 12 & 19 \\
Asian & 15 & 14 & 29 \\
Total & 305 & 288 & 593 \\
\hline
\end{tabular}

Man PCR core reagents (Kit No. 4304439) from Applied Biosystems. Universal PCR cycling conditions consisted of an initial $2 \mathrm{~min}$ at $50^{\circ} \mathrm{C}$ for activation of the AmpErase UNG, followed by a denaturation step of $10 \mathrm{~min}$ at $95^{\circ} \mathrm{C}$ to activate the AmpliTaq Gold, and then 40 amplification cycles of denaturation at $95^{\circ} \mathrm{C}$ for $15 \mathrm{~s}$ and $1 \mathrm{~min}$ of anneal/extension at $60^{\circ} \mathrm{C}$. Each quantitative PCR contained $45 \mu \mathrm{l}$ of PCR master mix and $5 \mu \mathrm{l}$ of DNA template and were carried out in $50 \mu 1$ using $1 \times$ TaqMan buffer and $0.5 \mathrm{U}$ AmpErase UNG as recommended by the supplier. Other reagents were optimized as follows. The duplex nDNA/mtDNA quantitative assay used $1 \mu \mathrm{M}$ primers, $100 \mathrm{nM}$ each probe, $0.5 \mathrm{mM}$ dNTPs, $5.0 \mathrm{mM} \mathrm{MgCl} 2$, and 2.5 U AmpliTaq Gold DNA polymerase. The triplex nDNA/mtDNA/male $\mathrm{Y}$ assay used $100 \mathrm{nM}$ nDNA primers, $600 \mathrm{nM}$ mtDNA primers, $1 \mu \mathrm{M}$ male $\mathrm{Y}$ primers, $100 \mathrm{nM}$ nDNA and mtDNA probes, $250 \mathrm{nM}$ male $Y$ probe, $0.2 \mathrm{mM}$ dNTPs, $3.0 \mathrm{mM}$ $\mathrm{MgCl}_{2}$, and $1.25 \mathrm{U}$ AmpliTaq Gold DNA polymerase.
The duplex $\mathrm{X} / \mathrm{Y}$ assay used $1 \mu \mathrm{M} \mathrm{X}$-chromosome primers, $200 \mathrm{nM}$ male Y-chromosome primers, $100 \mathrm{nM}$ each probe, $0.2 \mathrm{mM}$ dNTPs, $5.0 \mathrm{mM} \mathrm{MgCl}$, and $1.25 \mathrm{U} \mathrm{Amp}$ liTaq Gold DNA polymerase.

\section{DNA samples}

Human DNA standards were isolated from the HeLa cell line (ATCC CCL2; American Type Culture Collection, Manassas, VA) using Wizard genomic DNA purification (Promega, Madison, WI). Extracted DNA was stored in $10 \mathrm{mM}$ Tris/0.1 mM EDTA (TLE), quantified spectrophotometrically, and then serially diluted 10-fold in TLE such that concentrations from $100 \mathrm{ng}$ to $0.01 \mathrm{pg}$ were assayed in duplicate using PCR. Human male DNA standards (NA17055 and NA17316) were purchased from Coriell Cell Repositories and serially diluted as above. Human nuclear DNA was obtained from a human-rodent somatic cell hybrid panel from the NIGMS Human Genetic Mutant Cell Repository at Coriell Institute (Camden, NJ) (panel 2). DNA from pygmy chimpanzee (P. paniscus; NG05253), common chimpanzee (P. troglodytes; NG06939), and gorilla (G. gorilla; NG05251) were purchased from Coriell Cell Repositories. DNA from dog (Canis familiaris), cat (Felis catus), rabbit (Oryctolagus cuniculus), cow (Bos taurus), horse (Equus caballus), and sheep (Ovis aries) were obtained by tissue and blood extraction using the Wizard Genomic DNA Purification kit (Promega) and samples were provided by the Louisiana State University School of Veterinary 
Medicine. DNA from pig (Sus scrofa), deer (Odocoileus virginianus), rat (Rattus norvegicus), and mouse (Mus musculus) were prepared from tissue with proteinase $\mathrm{K}$ digestion followed by phenol:chloroform extraction and ethanol precipitation [11]. Chicken (Gallus gallus) DNA was extracted from blood using the QIAamp DNA blood mini kit (Qiagen, Valencia, $\mathrm{CA})$.

\section{Data analysis}

Separate standard curves were constructed for each component of the multiplex quantitative assays as follows. Data from duplicate human DNA standards were exported from the ABI Prism 7000 SDS software into a Microsoft Excel spreadsheet where the mean value and standard deviation were calculated for each point on the standard curve. Using the Excel trendline option, a line of best fit was plotted with Y-error bars equal to one standard deviation to form a standard curve. Data from the negative control (no-template control; NTC) duplicates and the "domestic DNA mixture" test samples (Table 2) (mean \pm one standard deviation of duplicates) were then plotted on the graph for comparison to the standard curve. Pairwise $t$ tests were performed to determine whether the NTC for each assay was statistically different from the minimum value on the standard curve $(p \leqslant 0.05)$.

Data from the multispecies cross-amplification experiments were exported to Excel in a similar manner and the mean and standard deviation of duplicates were calculated. The Excel chart wizard was used to construct bar graphs with Y-error bars equal to one standard deviation.

\section{Results}

Here, we report the development of a comprehensive set of human-specific, target-specific, multiplex PCR assays using TaqMan-MGB fluorescent-labeled probes, including the first reported triplex assay for the simultaneous detection and quantitation of human nDNA, mtDNA, and male Y DNA in a single reaction. The nuclear target in this multiplex quantification system is an intra-Alu PCR assay designed within the largely human-specific subfamily of $A l u \mathrm{Yb} 8$ elements (Fig. 1). There are about 1800 copies of the Alu Yb lineage elements in the human genome [12] and approximately 9 in the chimpanzee genome [13], giving a greater than 200-fold competitive PCR advantage to human targets. We modified a previously reported intra-Alu Yb8 quantitative assay that used SYBR green fluorescence detection [6] to create a multiplex-compatible, human-specific assay using universal PCR cycling conditions.
Assay specificity also dictated our design of a mitochondrial DNA target. The human genome project revealed that transfer of large mitochondrial fragments to the nucleus is a continuous evolutionary process and that essentially all parts of the human mitochondrial genome are represented somewhere in the nuclear genome [14]. We used analysis of existing DNA sequence databases to facilitate a large-scale comparison between the human mitochondrial genome, the human nuclear genome, and the mitochondrial genomes of other nonhuman primates to create a target-specific design.

The nDNA/mtDNA duplex qPCR assay had a linear quantitation range of $100-0.001 \mathrm{ng}(1 \mathrm{pg})$, or $10^{6}$, as shown by the standard curves (Fig. 4A) and was identical to separate monoplex runs of each assay (data not shown). The NTCs were detectable below the 1-pg level of $31.3 \pm 0.01$. The mean value of the nDNA NTC was $33.7 \pm 0.1 \quad(p=0.0282)$ and the mean value of the mtDNA NTC was $37.1 \pm 0.7(p=0.1238)$. This duplex assay detected the known values of human DNA from within a "domestic DNA mixture" containing dog and cat DNA from $50 \%$ (50 and $5 \mathrm{ng}$ ) to $0.05 \%(5 \mathrm{pg})$ as indicated by the open symbols along each standard curve. The compositions of the various DNA mixtures are shown in Table 2. Background cross-amplification with DNA templates derived from 14 other species, including 3 closely related nonhuman primate species, was negligible prior to 32 cycles of PCR for the nDNA component and absent for the mtDNA component (Fig. 4B). This further demonstrates that this duplex assay is human specific within its quantitative range. In addition to being human specific, both assay components were target specific in that the nDNA PCR product had no significant sequence identity to any portion of the human mitochondrial genome (BLAST 2 results; www.ncbi. nlm.nih.gov) and the mtDNA assay did not crossamplify with nDNA targets obtained from a humanrodent somatic cell hybrid panel (Fig. 4B).

The triplex qPCR assay (nDNA, mtDNA, and male Y DNA) had a linear quantitation range of $100-0.1 \mathrm{ng}$, or $10^{4}$, as shown by the three standard curves (Fig. 5A). The NTC was not detectable up to 40 cycles of PCR for any of the triplex components. The addition of the male $\mathrm{Y}$ locus to the nDNA/mtDNA duplex resulted in reduced assay sensitivity, but quantitative accuracy was maintained as the triplex assay detected from 50\% (50 and $5 \mathrm{ng})$ to $5 \%(0.5 \mathrm{ng}$ ) human DNA from the complex mixtures as indicated by the open symbols along each standard curve (Fig. 5A). Background cross-species amplification was negligible prior to 39 cycles of PCR for the nDNA component and absent for the mtDNA component. The male Y component of the triplex exhibited some cross-amplification with DNA templates derived from other primate species only, but since the other two components of the triplex are human specific, the assay is human specific within its quantitative range 

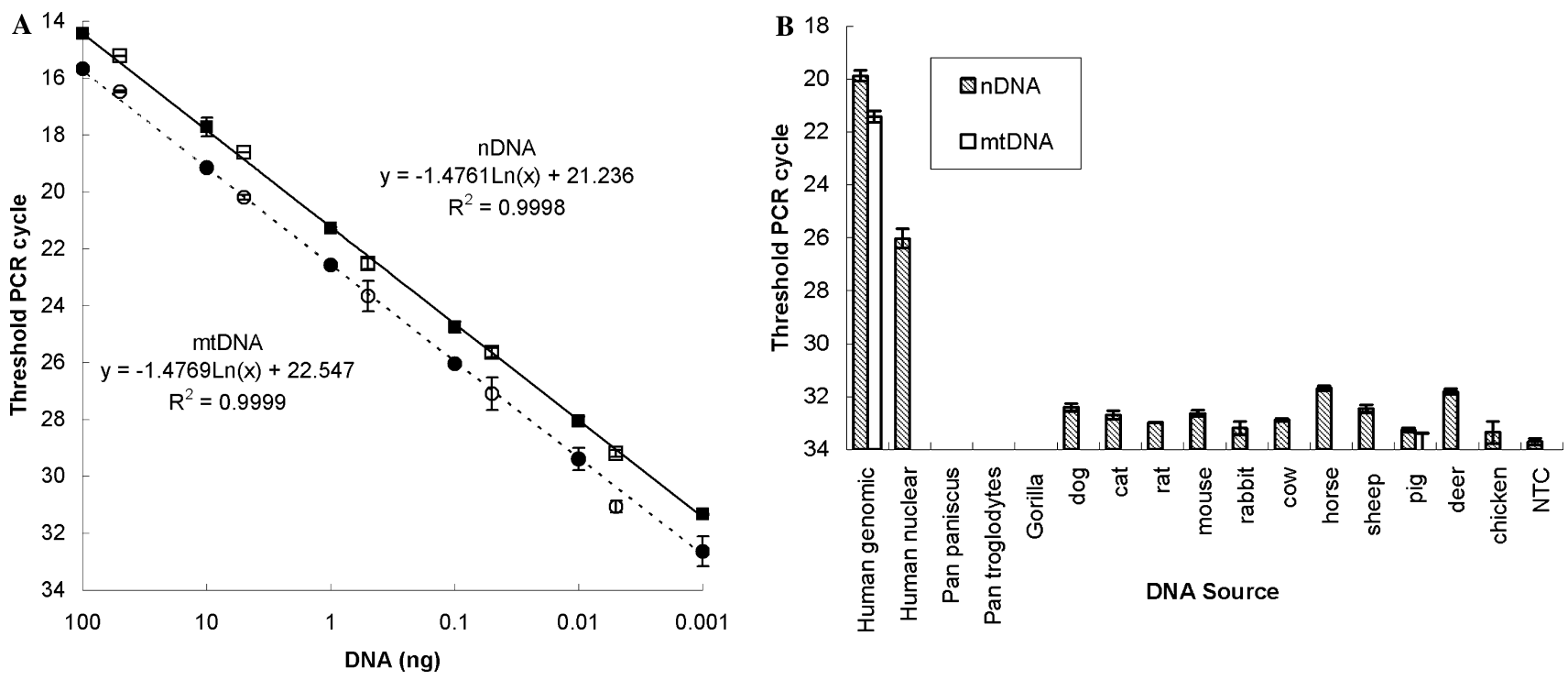

Fig. 4. (A) Effective quantitation range of the nDNA/mtDNA duplex PCR assay using TaqMan-MGB probes. The PCR cycle at which the fluorescent signal crosses baseline is considered to be the threshold cycle, plotted on the $y$ axis. The fluorescent signal produced by a 10-fold dilution series of human DNA is plotted as the mean of duplicates \pm 1 standard deviation. The $R^{2}$ value is $100 \%$ for both the nDNA standard curve (solid line with filled squares) and the mtDNA standard curve (dotted line with filled circles). Analyses of DNA mixtures 1-5 outlined in Table 2 are plotted in order as open symbols along each standard curve (squares or circles, respectively) as the mean of duplicates \pm 1 standard deviation. Their alignment along each standard curve demonstrates the ability of the duplex assay to simultaneously quantitate human nDNA and mtDNA from within a complex source of starting templates. (B) Background amplification of the nDNA/mtDNA duplex PCR assay using TaqMan-MGB probes. The PCR cycle at which the fluorescent signal crosses baseline is considered to be the threshold cycle, plotted on the $y$ axis as the mean of duplicates \pm 1 standard deviation. Human genomic DNA ( $2 \mathrm{ng}$ ) is compared to human nuclear DNA derived from a human-rodent somatic cell hybrid panel containing no human mtDNA and equal amounts of DNA template from 14 other species, including 3 other primate species. Background cross-species amplification was negligible prior to 32 cycles of PCR for the nDNA component and completely absent in the mtDNA component. This demonstrates that this duplex assay is human specific within its effective quantitative range.

(Fig. 5B). Cross-amplification among assay targets was still negligible as in the duplex nDNA/mtDNA assay. The male $\mathrm{Y}$ assay did not cross-amplify with human female DNA (Fig. 5B).

The human sex chromosome X/Y duplex correctly identified the gender of 95 individuals simultaneously on a single PCR plate (Fig. 6). A scatter plot of the threshold PCR cycle data for X (CT X, plotted on the $x$ axis) and male Y (CT Y, plotted on the $y$ axis) illustrates the ability of the duplex to identify gender. The NTC was not detectable up to 40 cycles of PCR. Using a Microsoft Excel spreadsheet, the data were analyzed to automate gender assignment.

\section{Discussion}

In this study we have designed and evaluated a comprehensive set of human-specific multiplex PCR assays for the rapid quantitation of human nuclear, mitochondrial, and sex chromosome DNA. Forensic DNA testing typically involves analysis of autosomal STRs, Y-chromosome STRs, or mitochondrial DNA sequence determination at the hypervariable regions 1 and 2 (HV-1 and HV-2). The decision to implement one or more of these approaches is based on several factors, such as the type of evidence, case history, quantity of evidence, supportive evidence, etc. The use of independent assays for human nuclear DNA, human male DNA, and mitochondrial DNA leads to consumption of valuable DNA evidence, which is typically available in limited quantity. The triplex assay reported here determines the quantities of DNA template required for all three types of DNA analysis in a single PCR, thereby consuming minimal DNA evidence in the course of determining which type of subsequent analyses should be performed.

Undoubtedly, the triplex assay for simultaneous quantification of human nDNA, mtDNA, and male Y DNA in a single PCR is the most efficient and informative of the assays presented here when unknown DNA evidence is being tested. The PCR amplification takes less than $2 \mathrm{~h}$ using universal cycling parameters on an ABI 7000 sequence detection system. Inclusion of human male and female DNA standards in the triplex assay allows for gender determination of unknown samples and serves as a positive control for samples that do not contain human DNA. The amount of DNA template typically required for STR analyses ranges from 0.1 to $2.0 \mathrm{ng}$ [1] and therefore falls within the linear quantitative range of this triplex PCR assay. Some reduction of PCR amplification efficiency occurs with the triplex compared to the nDNA/mtDNA duplex as noted by the 

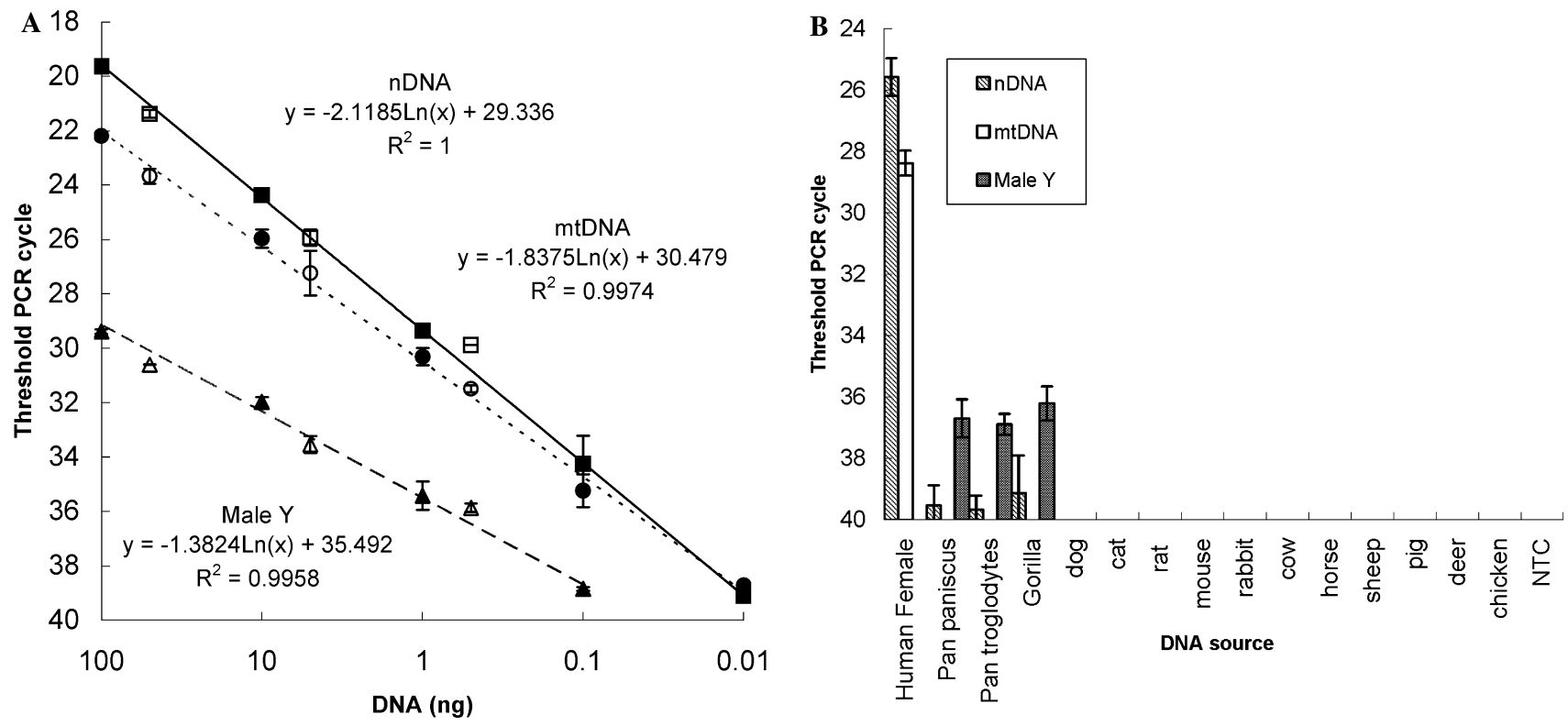

Fig. 5. (A) Effective quantitation range of the triplex PCR assay for the simultaneous quantification of human nDNA, mtDNA, and male Y DNA using TaqMan-MGB probes. The PCR cycle at which the fluorescent signal crosses baseline is considered to be the threshold cycle, plotted on the $y$ axis. The fluorescent signal produced by a 10-fold dilution series of human male DNA is plotted as the mean of duplicates \pm 1 standard deviation. The $R^{2}$ value is $99-100 \%$ for all three assay components, the nDNA standard curve (solid line with filled squares), the mtDNA standard curve (dotted line with filled circles), and the male Y standard curve (dashed line with filled triangles). Analyses of DNA mixtures 1-3 outlined in Table 2 are plotted in order as open symbols along each standard curve (squares, circles, or triangles, respectively) as the mean of duplicates \pm 1 standard deviation. Their alignment along each standard curve demonstrates the ability of the triplex assay to simultaneously quantitate human nDNA, mtDNA, and male Y DNA from within a complex source of starting templates. (B) Background PCR amplification of the triplex PCR assay for the simultaneous quantification of human nDNA, mtDNA, and male Y DNA using TaqMan-MGB probes. The PCR cycle at which the fluorescent signal crosses baseline is considered to be the threshold cycle, plotted on the $y$ axis as the mean of duplicates \pm 1 standard deviation. Human genomic DNA $(2 \mathrm{ng})$ is compared to equal amounts of DNA template from 14 other species, including 3 other primate species. Background cross-species amplification was negligible prior to 39 cycles of PCR for the nDNA component and completely absent for the mtDNA component. The male Y component of the triplex exhibited some cross-amplification within other primate species only.

slopes of each standard curve beginning to deviate from $3.33(100 \%$ amplification efficiency of a 10 -fold dilution series). The slopes were $4.81,4.26$, and 3.18 for the nDNA, mtDNA, and male Y DNA assay components, respectively. This is not unexpected according to the Applied Biosystems Sequence Detection Systems Chemistry Guide. Multiplex PCR chemistry becomes increasingly more complex as the number of targets increases. The more abundant targets of nDNA and mtDNA had to be primer limited to permit efficient amplification of the less abundant male $\mathrm{Y}$ target. This phenomenon is not unique to TaqMan-based chemistry and is a common obstacle in multiplex assay design. However, the $R^{2}$ value for each standard curve remained near $100 \%$ in the triplex assay, allowing for accurate quantitation of each component simultaneously.

Development of a comprehensive set of human-specific multiplex quantitative PCR assays like those reported here allows investigators to select the most appropriate for the circumstances. If the expected amount of recoverable DNA evidence is below $0.1 \mathrm{ng}$, then the nDNA/mtDNA duplex assay may be a better choice than the triplex. The 100-fold increase in sensitivity of the duplex (down to $1 \mathrm{pg}$ ) may effectively quantitate trace amounts of DNA such that recent advancements in whole-genome amplification technology could be employed as a useful strategy [15]. Also, if the DNA source is known to be female only, then the duplex assay would be more appropriate than the triplex.

If the situation likely involves both male and female DNA, such as in sexual assault cases, $\mathrm{X}$ and $\mathrm{Y}$ chromosome STR analyses are typically used to determine whether there are multiple contributors and to sort out the relative contributions of male and female DNA. This limits the need for an $\mathrm{X} / \mathrm{Y}$ quantitative assay in typical forensic applications. However, a duplex X/Y quantitation assay may be useful in the detection of rare sex chromosomal disorders such as Klinefelter's syndrome (XXY) and XYY syndrome.

More importantly, this recently discovered human Xchromosome deletion represents an alternative to the use of the Amelogenin locus for a high-throughput system for human gender determination. Several researchers have recommended that Ameloginin not be relied upon as the sole determinant of gender [16-19] and this $\mathrm{X} / \mathrm{Y}$ duplex assay may provide a useful alternative. The PCR amplification takes less than $2 \mathrm{~h}$ using universal cycling parameters on an ABI 7000 sequence detection system 


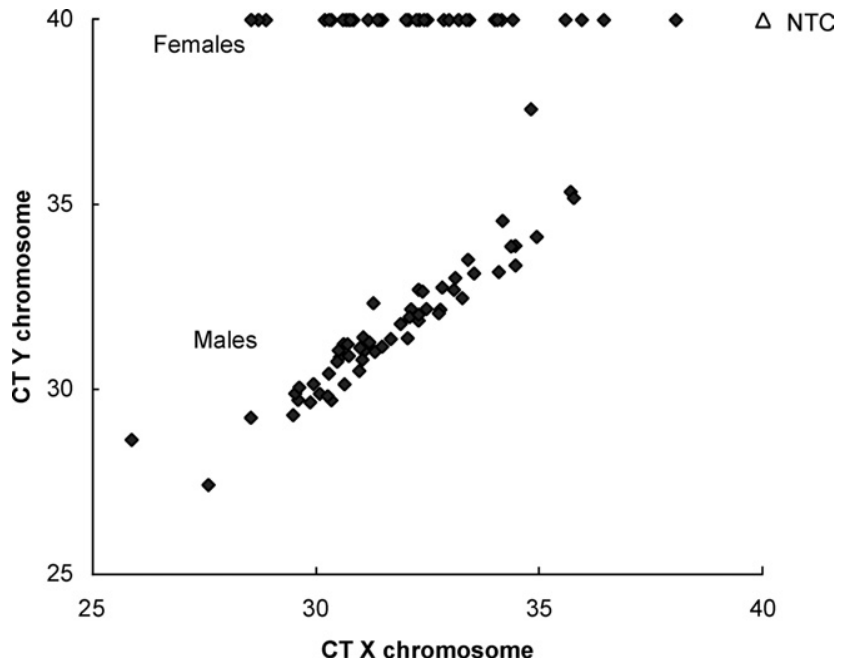

Fig. 6. Human gender determination using the X/Y duplex PCR assay. Scatter plot of the threshold PCR cycles (CT) for X chromosome detection ( $x$ axis) and $\mathrm{Y}$ chromosome detection ( $y$ axis) illustrates the utility of this assay for high-throughput human gender identification. Males exhibit fluorescent signal for both sex chromosomes while females exhibit signal only for the X chromosome. The NTC (open triangle) exhibits no signal.

and can be performed as an endpoint assay using a conventional thermal cycler and a fluorescent plate reader. The fact that it is fluorescent based and multiplex compatible and can be automated may make it a useful tool when large-scale gender verification is required such as in the Olympic games when several thousand athletes need to be genotyped [20].

Although similar methods have been reported previously, there are several advantages to our human-specific multiplex PCR systems. First, we have designed our assays to meet strict specifications. They must be human specific, target specific, and multiplex compatible. The previously reported methods do not meet all three of these criteria. The ability to multiplex the different assays was achieved by using Primer Express universal cycling parameters (Applied Biosystems) to design each assay, followed by systematic optimization of PCR reagent concentrations. Assay specificity was achieved by careful comparison of the intended target sequences to other genomes and then systematic evaluation of the assays for cross-amplification. Our male $\mathrm{Y}$ assay exhibited some cross-species amplification with DNA derived from other primate species. Since this assay is based on a human X-deletion, other primate species which lack the deletion would be expected to have sequence similar to the human male $\mathrm{Y}$, especially since the sex chromosomes have reduced evolutionary polymorphism rates compared to their autosomal counterparts [10]. This was confirmed by a BLAT search of the chimpanzee genome (http://genome.ucsc.edu/cgi-bin/hgBlat) using the PCR product used in this study which resulted in a $100 \%$ match on the chimpanzee Y chromosome. However, since our male $\mathrm{Y}$ assay is used as part of a multiplex, the background amplification signal in other primates does not affect assay specificity. Furthermore, the sequence similarity to other primate genomes can make one fairly certain that this male $\mathrm{Y}$ locus is fixed in all human males.

Another advantage to our multiplex qPCR assays is the high-copy-number target used in our intra-Alu $\mathrm{Yb} 8$ nDNA assay compared to single-copy targets used in previous methods $[8,9]$. The quantitative range of our nDNA assay is $10^{6}$ with a minimum effective quantitation level of $1 \mathrm{pg}$ of DNA. This exceeds previously reported multiplex-compatible nDNA quantitation assays by a minimum of threefold [9]. In addition, our PCR assays involve the amplification of smaller PCR products and should be more tolerant of degraded DNA. Our nDNA amplicons are $7 \mathrm{bp}(9 \%)$ [9] and $35 \mathrm{bp}$ (33\%) [8] shorter, our mtDNA amplicons are $63 \mathrm{bp}$ (44\%) [9] and $34 \mathrm{bp} \mathrm{(30 \% )} \mathrm{shorter,} \mathrm{and} \mathrm{our} \mathrm{X/Y} \mathrm{ampli-}$ cons are $29 \mathrm{bp}(27 \%)$ and $43 \mathrm{bp}(38 \%)$ shorter [8].

We have demonstrated that these multiplex PCR assays for the rapid quantitation of human nuclear, mitochondrial, and sex chromosome DNA are human specific, target specific, and multiplex compatible. Having all three of these criteria represents a significant advantage over currently available methods. Our systems also include the first reported triplex PCR assay for the simultaneous quantification of nDNA, mtDNA, and male Y DNA in a single PCR. Mainstream application of these novel human-specific multiplex PCR assays will undoubtedly be a valuable tool for forensic genomics.

\section{Acknowledgments}

This research was supported by the Louisiana Board of Regents Governor's Biotechnology Initiative GBI (2002-005) (M.A.B.), National Science Foundation EPS0346411 (M.A.B.), and the State of Louisiana Board of Regents Support Fund (M.A.B.). Benjamin Perodeau was supported by National Institutes of Health P20 RR16456 from the BRIN program of the National Center for Research Resources. Nadica Stoilova and Meredith Laborde were supported by a Howard Hughes Medical Institute grant through the Undergraduate Biological Sciences Education program to Louisiana State University.

\section{References}

[1] W.E. Frank, B.E. Llewellyn, P.A. Fish, A.K. Riech, T.L. Marcacci, D.W. Gandor, D. Parker, R.R. Carter, S.M. Thibault, Validation of the AmpFiSTR Profiler Plus PCR amplification kit for use in forensic casework, J. Forensic Sci. 46 (2001) 642-646.

[2] D. Bogenhagen, D.A. Clayton, The number of mitochondrial deoxyribonucleic acid genomes in mouse $\mathrm{L}$ and human $\mathrm{HeLa}$ 
cells. Quantitative isolation of mitochondrial deoxyribonucleic acid, J. Biol. Chem. 249 (1974) 7991-7995.

[3] J.C. Fox, C.A. Cave, J.W. Schumm, Development, characterization, and validation of a sensitive primate-specific quantification assay for forensic analysis, Biotechniques 34 (2003) 314322.

[4] J.A. Nicklas, E. Buel, Development of an Alu-based, real-time PCR method for quantitation of human DNA in forensic samples, J. Forensic Sci. 48 (2003) 936-944.

[5] M.E. Sifis, K. Both, L.A. Burgoyne, A more sensitive method for the quantitation of genomic DNA by Alu amplification, J. Forensic Sci. 47 (2002) 589-592.

[6] J.A. Walker, G.E. Kilroy, J. Xing, J. Shewale, S.K. Sinha, M.A. Batzer, Human DNA quantitation using Alu element-based polymerase chain reaction, Anal. Biochem. 315 (2003) 122-128.

[7] J.A. Nicklas, E. Buel, Development of an Alu-based QSY 7labeled primer PCR method for quantitation of human DNA in forensic samples, J. Forensic Sci. 48 (2003) 1-10.

[8] A. Alonso, P. Martin, C. Albarran, P. Garcia, O. Garcia, L.F. de Simon, J. Garcia-Hirschfeld, M. Sancho, C. de la Rua, J. Fernandez-Piqueras, Real-time PCR designs to estimate nuclear and mitochondrial DNA copy number in forensic and ancient DNA studies, Forensic Sci. Int. 139 (2004) 141-149.

[9] H. Andreasson, U. Gyllensten, M. Allen, Real-time DNA quantification of nuclear and mitochondrial DNA in forensic analysis, Biotechniques 33 (2002) 402-411.

[10] P.A. Callinan, D.J. Hedges, A.H. Salem, J. Xing, J.A. Walker, R.K. Garber, W.S. Watkins, M.J. Bamshad, L.B. Jorde, M.A. Batzer, Comprehensive analysis of Alu-associated diversity on the human sex chromosomes, Gene 317 (2003) 103-110.
[11] W.M. Strauss, in: W.M. Ausubel (Ed.), Current Protocols in Molecular Biology, Wiley, New York, 1998, pp. 2.2.1-2.2.3.

[12] A.B. Carter, A-.H. Salem, D.J. Hedges, C.N. Keegan, B. Kimball, J.A. Walker, W.S. Watkins, L.B. Jorde, M.A. Batzer, Genome-wide analysis of the human Alu Yb-lineage, Human Genomics 1 (2004) $167-178$.

[13] R. Gibbons, L.J. Dugaiczyk, T. Girke, B. Duistermars, R. Zielinski, A. Dugaiczyk, Distinguishing humans from great apes with AluYb8 repeats, J. Mol. Biol. 339 (2004) 721-729.

[14] T. Mourier, A.J. Hansen, E. Willerslev, P. Arctander, The Human Genome Project reveals a continuous transfer of large mitochondrial fragments to the nucleus, Mol. Biol. Evol. 18 (2001) 1833 1837.

[15] K.J. Sorensen, K. Turteltaub, G. Vrankovich, J. Williams, A.T. Christian, Whole-genome amplification of DNA from residual cells left by incidental contact, Anal. Biochem. 324 (2004) 312-314.

[16] F.R. Santos, A. Pandya, C. Tyler-Smith, Reliability of DNA-based sex tests, Nat. Genet. 18 (1998) 103.

[17] M. Steinlechner, B. Berger, H. Niederstatter, W. Parson, Rare failures in the amelogenin sex test, Int. J. Legal Med. 116 (2002) 117 120.

[18] K. Thangaraj, A.G. Reddy, L. Singh, Is the amelogenin gene reliable for gender identification in forensic casework and prenatal diagnosis?, Int. J. Legal Med. 116 (2002) 121-123.

[19] B. Brinkmann, Is the amelogenin sex test valid?, Int. J. Legal Med. 116 (2002) 63.

[20] A. Serrat, A. Garcia deHerreros, Gender verification in sports by PCR amplification of SRY and DYZ1 Y chromosome specific sequences: presence of DYZ1 repeat in female athletes, Br. J. Sports Med. 30 (1996) 310-312. 